\title{
Concomitant Aortoplasty with Septal Myectomy for Supravalvar Aortic Stenosis in an Adult
}

\author{
Raja Saravanan Elumalai ${ }^{1 *}$, Kirthivasan Vaidyanathan ${ }^{1}$, Madhu Sankar Nainar ${ }^{2}$, \\ Karthik Vaidyanathan ${ }^{2}$, Govini Balasubramaniam², Susan George ${ }^{3}$ \\ ${ }^{1}$ Department of Cardiac Anaesthesiology, Global Hospital and Health City, Perumbakkam, India \\ ${ }^{2}$ Department of Cardiothoracic Surgery, Global Hospital and Health City, Perumbakkam, India \\ ${ }^{3}$ Department of Cardiology, Global Hospital and Health City, Perumbakkam, India \\ Email: *drajasaravanan@gmail.com
}

Received December 3, 2011; revised January 13, 2012; accepted February 13, 2012

\begin{abstract}
Survival of patients with severe congenital aortic stenosis beyond third decade is uncommon. This report describes a 31 year old patient who underwent successful aortoplasty and in addition septal myectomy for complete relief of left ventricular outflow obstruction.
\end{abstract}

Keywords: Aortoplasty; Myectomy; Supravalvar Aortic Stenosis

\section{Introduction}

Congenital Supravalvar Aortic Stenosis is a rare form of obstructive lesion of the left ventricular outflow tract. The defining feature of the malformation is an aortic narrowing at the level of the sino tubular junction. The commonly associated lesions include peripheral pulmonary artery lesions, coronary lesions, abnormalities of the aortic leaflets and diffuse narrowing of ascending aorta. Survival beyond three decades is uncommon and this report describes a case of supravalvar aortic stenosis in a 31 year old patient who underwent successful aortoplasty and septal myectomy.

\section{Case Summary}

A 31 years old lady with symptoms of class III dyspnea, intermittent chest pain and syncopal attacks of 2 years duration was referred to our institute. Two Dimensional Echocardiography revealed discrete hour glass type of Supravalvular Aortic Stenosis with severe left ventricular hypertrophy (Figure 1). Left ventricle to aorta peak gradient was $163 \mathrm{~mm} \mathrm{Hg}$ with a mean of $101 \mathrm{~mm} \mathrm{Hg}$. She underwent surgical repair using cardiopulmonary bypass and blood cardioplegic arrest.

Inverted Y shaped Aortotomy was done with limbs extending into non and right coronary sinus. The aortic valve was tricuspid and competent Intraluminally the posterior ridge above left coronary sinus was excised. There was severe obstructive hypertrophy of septum and hence septal myectomy was done. The aortotomy was

"Corresponding author.

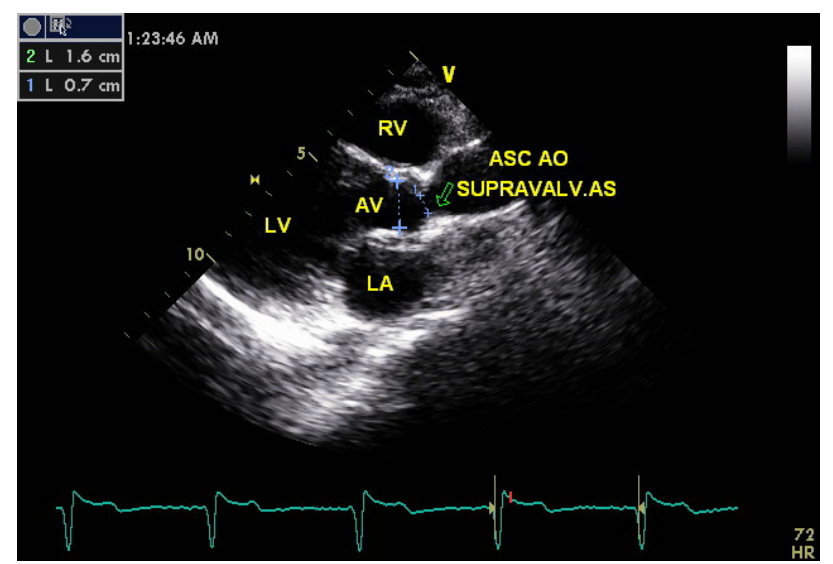

(RV: Right ventricle, LV: Left ventricle, AV: Aortic valve, LA: Left atrium, ASC AO: Ascending aorta, SUPRAVALV.AS: Supravalvular aortic stenosis)

Figure 1. Preoperative echo showing hour glass lesion of aorta.

closed with inverted $\mathrm{Y}$ shaped pericardial patch extending into the non coronary sinus and right coronary sinuses. The post operative recovery was uneventful .Pre discharge echocardiography (Figure 2(a)) and CT angiographic study (Figure 2(b)) showed a wide open LVOT with a peak gradient of $20 \mathrm{~mm} \mathrm{Hg}$ and mean of $12 \mathrm{~mm} \mathrm{Hg}$.

Ethics Committee approval and patient consent for publication of this data was obtained.

\section{Discussion}

Congenital supravalvular aortic stenosis often presents in 


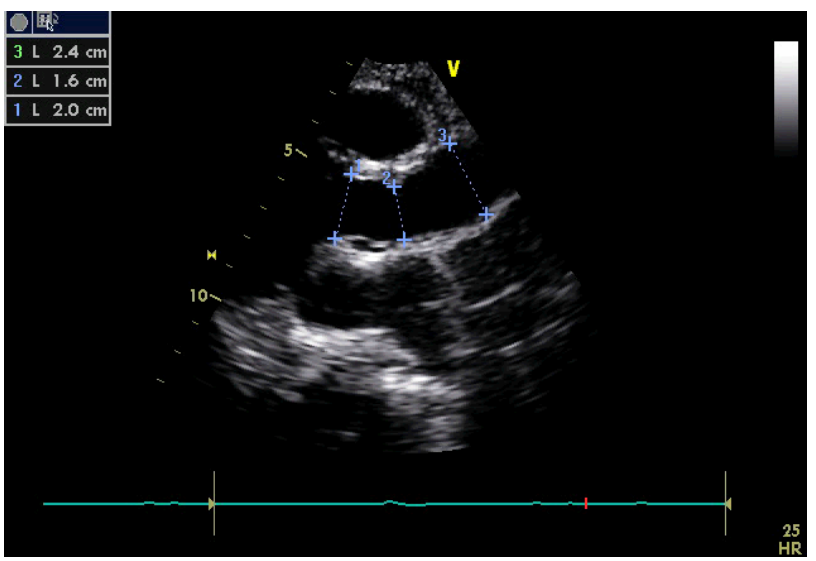

(a)

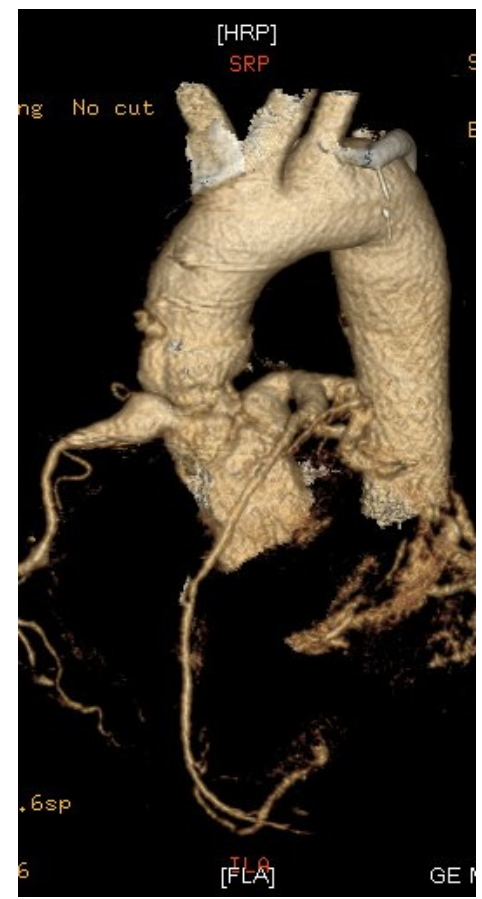

(b)

Figure 2. (a) Postoperative echo showing Left Ventricular Outflow Tract; (b) Postoperative 64 slice Computed Tomography of Aortic arch.

childhood and if not corrected by surgery can lead to heart failure and death. The defining feature is a focal or diffuse narrowing starting at the Sino tubular junction and often involving the entire ascending aorta with rare involvement of the aortic arch and occasionally the peripheral arterial system [1]. This disorder occurs in an autosomal inherited from and in a rare sporadic form it is frequently associated with Williams-Beuren syndrome [2]. The underlying cause has been identified as a mutation of the elastin gene on chromosome 7q11.23 [3]. The first report was in 1878 by Archer who described an elastic band stretching across distal to the aortic cusps [4]. First successful surgical repair with standard patch was described by McGoon in 1961 [5]. Doty et al described extended aortoplasty with bifurcated patch in 1977 which allows more symmetric enlargement of the aortic root [6]. Brom described enlarging all the 3 sinuses with ascending aorta enlargement by an additional patch [7]. Surgical treatment of supravalvar aortic stenosis by augmenting the aortic root in 2 or 3 sinuses of Valsalva is associated with a lower mortality rate and fewer reoperations as it preserves the anatomy of the aortic root with better physiologic flow. Currently, septal myectomy is recommended in patients undergoing aortic valve replacement for aortic stenosis with severe basal septal hypertrophy, as it leads to better regression of left ventricular hypertrophy due to more effective reduction of left ventricular outflow tract gradient [8]. The prognosis of supravalvular aortic Stenosis is poor and survival to adulthood without intervention is unusual. The outflow obstruction can be relieved by patch aortoplasty and septal myectomy with good results.

\section{REFERENCES}

[1] A. Wessel, R. Pankau, D. Kececioglu, W. Ruschewski, J. H. Buersch, "Three Decades of Follow-Up of Aortic and Pulmonary Vascular Lesions in the Williams-Beuren Syndrome,” American Journal of Genetics, Vol. 52, 1994, pp. 297-301. doi:10.1002/ajmg.1320520309

[2] C. A. Morris and C. B. Mervis, "Williams Syndrome and Related Disorders," Annual Review of Genomics and Human Genetics, Vol. 1, 2000, pp. 461-484.

[3] M. T. Keating, "Genetic Approaches to Cardiovascular Disease. Supravalvular Aortic Stenosis, Williams Syndrome, and Long-QT Syndrome,” Circulation, Vol. 92, No. 1, 1995, pp. 142-147.

[4] R. S. Archer, "Note on a Congenital Band Stretching across the Origin of the Aorta," Dublin Journal of Medical Science, Vol. 65, 1878, pp. 405-406.

[5] D. C. McGoon, H. T. Mankin, P. Vlad and J. W. Kirklin, "The Surgical Treatment of Supravalvular Aortic Stenosis," Journal of Thoracic and Cardiovascular Surgery, Vol. 41, 1961, pp. 125-133.

[6] D. B. Doty, D. B. Polansky and C. B. Jenson, "Supravalvular Aortic Stenosis Repair by Extended Aortoplasty," Journal of Thoracic and Cardiovascular Surgery, Vol. 74, 1977, pp. 362-371.

[7] M. G. Hazekamp, A. P. Kappetein, P. H. Schoof, J. Ottenkamp, M. Witsenburg, H. A. Huysmans and A. J. J. C. Bogers, "Brom's Three-Patch Technique for Repair of Supravalvular Aortic Stenosis,” Journal of Thoracic and Cardiovascular Surgery, Vol. 118, No. 2, 1999, pp. $252-$ 258. doi:10.1016/S0022-5223(99)70215-1

[8] N. Kayalar, H. Schaff, R. C. Daly, J. A. Dearani and S. J. Park, "Concomitant Septal Myectomy at the Time of Aortic Valve Replacement for Severe Aortic Stenosis," Annals of Thoracic Surgery, Vol. 89, No. 2, 2010, pp. 459-464. doi:10.1016/j.athoracsur.2009.10.065 